\title{
ENHANCING THE DONOR POOL: A REVIEW OF FINANCIAL INCENTIVES
}

\section{Tumin M, Ndoma I}

Faculty of Economics and Administration, University of Malaya, Kuala Lumpur, Malaysia.

\begin{abstract}
:
As the debate on accepting financial incentives persists, more and more findings linked to its success as well as to its foreseeable backlash continue to unravel. Specifically out to enhance perceptions on financial incentives, this paper reviews important aspects of the financial incentives and provides a diverse range of empirical findings at a glance. Through a review of several empirical findings and literature, this paper argues that several basic practices of the financial incentives are indeed instrumental to enhancing organ donation. However, more experimentation is necessary to unearth the best mode that is best responsive to a society and subsequently, rejects the overly generalization that labels it as unethical. (JUMMEC 2010; 13(2): 102-106)
\end{abstract}

KEYWORDS: organ donation, donor pool, financial incentives

\section{Introduction}

The state of organ shortage is no longer a new topic, so also are the methods used to procure them. However, the overarching debate rests on which method is ethical and which is not, thus, systematically blurring the most effective model that will make significant impact by saving more lives. The increasing deaths of patients awaiting transplantation are usually due to a deficit of donated organs against a huge demand score. It is discernible that the roots of this asymmetry lie in the acute shortfall in altruism and skepticism in the integrity of the financial incentives thereby, causing a huge gap in the course of increasing the donor pool. As a consequence, it has not only aggravated organ shortage, but has opened several controversial procurement alternatives like xenotransplantation that involves the transplantation of organs from one specie to another specie, commonly harvested from pigs and transplanted in humans (1), as well as the practice of harvesting organs from executed prisoners as practiced in China, regardless, neither of the prisoner's consent prior to execution nor of his family's after execution (2).

At this moment, the U.S has a staggering backlog of 110,135 patients on the waiting list as compared to just about 38, 000 in 1994 (3), and for patients awaiting kidney transplant, Malaysia in October 2010 has 11,000 registered patients on the waiting list (4) as against 5,542 in 1999 (5). These figures are disturbing, and much of this problem is closely tied to sole inclination to altruism which conversely has been overstretched and lacks the capacity to cushion the rising organ shortage. Undoubtedly the ethical and strict principles that saturate the altruistic method as well as, the rejection of financial incentives by many are major impediments aggravating organ shortage.

In spite of the fact that financial incentives has been remarkable in drastically reducing organ shortage (6, $7,8)$, it has also been seen as unproductive, unethical and regressive to altruism by others $(9,10,11,12)$, unfortunately heralding few supporters and many opponents (13) and hence, further straining the chances of enhancing the donor pool.

\section{Correspondence:}

Ibrahim Ndoma

Department of Development Studies

Faculty of Economics and Administration

University of Malaya

50603 Kuala Lumpur, Malaysia

Email: Ibrahim.ndoma@yahoo.com 
It is on these notes that this review sets out to provide grounds for a reconsideration of the financial incentives as a viable alternative. It proceeds by briefly throwing light to what the financial incentives entail, and subsequently sets the stage for an in depth review of empirical findings from where pros and cons of the financial incentives are extricated and discussed. It then moves on in the concluding section to provide its take on the financial incentives by shedding light on the need for its reexamination and application to cushion organ shortage.

\section{Financial incentives model}

On hearing the word 'financial incentives', the first thing that comes to mind is the blatant use of money to procure organs for transplant. While this is comprehensible at least for laypersons, it is essential that we provide a brief insight to what the financial incentives is all about. This model involves a wide range of practices advocated by theorists and medical experts particularly, with intent for gratification or compensation aimed at supporting the altruistic system as well as, to induce organ supply (13). The more common forms of the financial incentives include; direct payment by recipients to beneficiaries of the donor (14) and/or by the government to the donors (6); reimbursement of funeral expenses (9); provision of free health insurance and tax exemption (15); priority on the waiting list should a former donor seek donation $(16,17)$; contribution to a charitable organization determined by the donor or donor's family (10) and, also the futures market system where a prospective donor consents to donation subject to payment made to his beneficiaries after the organ is harvested (18).

\section{Empirical findings of studies on financial incentives}

From many empirical surveys, while other forms of financial incentives have been receptive and promising, direct payment to beneficiaries has not been popular. For instance, in a study conducted by Bryce et al. (19) on the relevance of financial incentives to beneficiaries of a deceased donor, the following were recorded: $81 \%$ in favour of funeral benefits; $73 \%$ in favour of charitable contributions; $78 \%$ in favour of travel/ lodging expenses and $84 \%$ in favour of travel expenses. But, response rate was considerably low as only $53 \%$ of the respondents subscribed to direct payment. Similarly Boulware et al. (20) discovered that public reception on direct payment for living donors is very low compared to other forms of financial incentives. In their study for instance, reimbursement of medical costs reported $91 \%$ acceptance rate, which is a sharp contrast to direct government payment to a donor and direct payment to a donor by a recipient, both of which, recorded an unimpressive $28 \%$ and $8 \%$ respectively (see also 17).

It is pertinent that direct payment has not been very popular due to the belief by many who have varying convictions that direct payment will neither make any significant impact on their lives nor will it entice them to donate. Similarly, others see it as a blatant way of selling the body parts of their loved ones which is often perceived as immoral and unconventional when reference is made to cultural and religious norms.

The varying forms of financial incentives system are geared towards inducing the consent of donors and their families for a cadaver donation. Consent for organ donation via financial incentives has always been fraught with skepticism which MayrhoferReinhartschuber and Fitzgerald (13) contend to be due to psychological or fear factor encountered by individuals, which supersedes the economic and medical gains. To this end, they employed the theory of cognitive dissonance developed by Festinger and Carlsmith (21) to provide explanations to the psychological barriers that inhibit the popularity of the financial incentives system as well as, the best approach to ameliorating the flaws. Furthermore, Ghods and Savaj (6) provide a coherent description as to how the fear factor and other impediments were eliminated in Iran, so much so that the waiting list was virtually eliminated through a more radical and controversial method which has been highly prohibited by most legislations around the world - Living-unrelated organ donation.

From diverse recorded data compiled on kidney donation in Iran, Ghods and Savaj (6) concluded that as at the end of 2005, a total of 19,609 renal transplantations were carried out, of which 3421 came from living-related donors, 15,365 from living-unrelated donors, and 823 from deceased donors. The success of the living-unrelated donation simply overarches all other procurement methods thus, systematically 
providing the impetus that makes all other methods successful and responsive to organ procurement. The incentives behind the success of the Iranian model are well coordinated sets of procedures which have been described as follows (p. 1137-1138):

...after renal transplantation, the living-unrelated donor receives an award and health insurance from the government. A majority of living-unrelated donors also receive a rewarding gift (arranged and defined by Dialysis and Transplant Patients Association or DATPA before transplantation) from the recipient or, if the recipient is poor, from one of the charitable organizations. The government also provides essential immunosuppressive drugs such as cyclosporine neoral and mycophenolate mofetil to all transplant recipients at a greatly subsidized and reduced price. Charitable organizations also are very active in providing these drugs or in paying any expenses of renal transplantation to poor patients...

It is discernible from further descriptions provided by Ghods and Savaj (6) and Larijani et al. (8), that the government is the main actor that encourages, coordinates and regulates the whole organ donation process that ensued to the remarkable success attained.

Complementing the foregoing, Van Dijk and Hilhorst (17) in a report submitted for policy review on the financial incentives system in the Netherlands, recommended that small incentives like discount on health insurance premiums and priority on the waiting list should be offered to people registering as donors, simply to induce them as well as expel all skepticism that could impede on decisions of a prospective donor to donate.

However, Bryne and Thompson (22), exploring this notion from the perspective of cadaver donation reject the notion that financial incentives will serve as an inducement for donors to consent to organ donation in the event of death. Using statistical analysis, they concluded that rewards for registration to a potential donor naturally leads to time inconsistency problem as donors may rescind their donor status at will. What this means is that the likelihood to donate rests on their preference parameter and not the reward. They also added that rewards to potential donors distort the signal contents of their decisions since they are not going to benefit from rewards derived from cadaveric donation. As such, it is the family's preference devoid of the financial incentives offered, that counts.

Possible setbacks inherent in the preceding study rest with the binding principle prospective donors are subjected to which tends to make them feel indebted. This underscores the results obtained by Kranenburg et al. (23) whose study on public perception on the financial incentives reports a majority of respondents subscribing to a system wherein the donor would register at an independent institute to donate to a patient on the list and in turn receive life-long health insurance compensation, as against a situation wherein health insurance companies would introduce financial incentives to increase the number of living kidney donors.

\section{Conclusion}

The perspectives and findings of various studies on the financial incentives cannot and should not be generalized to be applicable to all socio-political and cultural settings, due to several value systems that are at play. What is acceptable to a socio-political setting may otherwise be rejected by another. Also, it should not be forgotten that different studies employed different techniques which are not necessarily designed to produce the same results when applied to a completely different setting.

From the studies examined, it is evident that most respondents would prefer medical or funeral reimbursements and life medical insurance as against direct payment. While this is acceptable at a superficial level, there is the likelihood that individuals from poverty stricken areas would respond differently by embracing direct payment. This assertion is in tandem with the findings of Rid et al. (24), whose respondent's status is in high and middle socio-economic categories. However, out of a total sample of 179 respondents, a majority specifically, 48 (27\%) respondents considered the likelihood of selling a kidney in a regulated kidney market, out of whom, $31(66 \%)$ would sell only to overcome a particularly difficult financial situation. This simply informs us that there are several factors that determine the success of the financial incentives system. As such, all financial incentive models are indeed relevant to enhancing the donor pool provided they are in consonance with the socio-religious, 
economic and political values of a particular group of people or community.

The case of Iran is a good example. Judging from the successes of the Iranian model as a prototype of organ donation, one would expect a country with serious backlog of waiting lists like the U.S to quickly emulate. However that is not the case perhaps due to varying values and political documents that distinctly separate the U.S from Iran.

Since several ethical practices and dimensions of the financial incentives abound, it is imperative that policy makers and society as whole come to the realisation that effective enhancement of the donor pool requires a radical integration of various approaches of organ donation, provided they are tested and found to be in conformity with rules and values governing a society.

At this point, the baton for the success of the financial incentive rests with society and until society charges stakeholders to act, survival and prospect for normal livelihood of patients remain bleak.

\section{References}

1. Cooper DKC, Gollackner B, Sachs DH. Will the pig solve the transplantation backlog? Annal Rev of Med 2002; 53: 133-147.

2. Perales DJ. Rethinking the prohibition of death row prisoners as organ donors: a possible lifeline to those on organ donor waiting lists. St. Mary's Law J 2003; 34(3): 687-732.

3. United Network for Organ Sharing. Available at: http://www.unos.org/data/default.asp?display Type=usData. Accessed on 15 Dec 2010.

4. The Star Online. Over 11,000 patients in transplant waiting list. Available at: http://www.thestar.com. $\mathrm{my} /$ news/story.asp? sec $=$ nation\&file $=/ 2010 / 10 / 18 /$ nation/7245718. Accessed 18 Oct 2010

5. National Renal Registry Malaysia. 16th report of the Malaysian Dialysis and Transplant Registry, Chapter 1 2010; Available at: http://www.msn.org.my/nrr.

6. Ghods AJ, and Savaj S. Iranian Model of paid and regulated living-unrelated kidney donation. CJASN 2006; 1: 1136-1145.
7. Matas AJ. Why we should develop a regulated system of kidney sales: a call for action. CJASN 2006; 1(6): 1129-1132.

8. Larijani B, Zahedi F, Taheri E. (2004) Ethical and legal aspects of organ transplantation in Iran. Transplant Proc 2004; 36(5): 1241-1244.

9. Delmonico FL, Arnold R, Scheper-Hughes, N, et al. Ethnical incentives - not payment - for organ donation. N Eng J Med 2002; 346(25): 2002-2005.

10. Arnold R, Bartlett S, Bernat J, et al. Financial incentives for cadaver organ donation: an ethical reappraisal. Transp/ 2002; 73(8): 1361-1367.

11. Rothman DJ. Ethical and social consequences of selling a kidney. JAMA 2002; 288(13): 1640-1641.

12. Daar AS. The case for a regulated system of living kidney sales. Nat Clinl Prac Neph 2006; 2(11): 600601.

13. Mayrhofer-Reinhartshuber D, Fitzgerald R. Financial incentives for cadaveric organ donation. Annals Transplant 2004; 9(1): 25-27.

14. Lysaght MJ, Mason J. The case for financial incentives to encourage organ donation. ASAIO J 2000; 46(3): 253-256.

15. Abouna G. Organ shortage crisis: problems and possible solutions. Transplant Proc 2008; 40(1): 3438.

16. Delmonico FL, Morrissey PE, Lipkowitz GS, et al. Donor kidney exchanges. Am J of Transplant 2004; 4: 1628-1634.

17. Van Dijk G, Hilhorst MT, eds Financial Incentives for Organ Donation: An Investigation of the Ethical Issues. The Hague: Center for Ethics and Health; 2007.

18. Cohen LR. Increasing the supply of transplant organs: the virtues of a futures market. $G$ Washington L Rev 1989; 58(1): 1-51.

19. Bryce $C L$, Siminoff $L A$, Ubel $P A$, et al. Do incentives matter? providing benefits to families of organ donors. Am J Transplant 2005; 5: 2999-3008.

20. Boulware LE, Troll MU, Wang NY, et al. Public attitudes toward incentives for organ donation: 
a national study of different racial/ethnic and income groups. Am J Transplant 2006; 6(11): 27742785 .

21. Festinger L, Carlsmith JM. Cognitive consequence of forced compliance. J Abnorm Soc Psych 1959; 58(2): 203-211.

22. Bryne MM, Thompson P. A positive analysis of financial incentives for cadaveric organ donation. $J$ Health Econ 2001; 20(1): 69-83.
23. Kranenburg L, Schram A, Zuidema W, et al. Public survey of financial incentives for kidney donation. Nephrol Dial Transplant 2008; 23: 1039-1042.

24. Rid A, Bachmann LM, Wettstein V. et al. Would you sell a kidney in a regulated kidney market? Results of an Exploratory Study. J Med Ethics; 35(9): 558564. 